\title{
Sentido y función del intelectual en el pensamiento de Eugenio Imaz
}

\author{
JOSÉ ANGEL ASCUNCE ARRIETA \\ Universidad de Deusto
}

Existe en la vida de Eugenio Imaz, como en la de muchos españoles del tiempo histórico del ensayista donostiarra, un acontecimiento clave que va a marcar dramáticamente tanto su psicología como su pensamiento: la guerra civil. Antes de la guerra civil casi todos los escritos de Eugenio Imaz presentan un fundamento historicista y político, siempre enmarcado en el presente histórico, pero tratado con un enfoque plenamente teórico y universalista. Se puede afirmar que el filosofo vasco es un hombre preocupado por la historia y el destino pero a un nivel intelectual y no tanto social. (Eso es lo que demuestran sus escritos, aunque es verdad que como persona, en su fuero interno, podía sentirse plenamente inmerso en la vorágine histónica de su momento. Pero todos sus ensayos callan al respecto.) En torno al tratamiento de cultura intelectual, Eugenio Imaz lo trata en distintas ocasiones desde presupuestos lógicamente teóricos y con un planteamiento muy general. Desde esta perspectiva, aunque en diversos momentos habla de los intelectuales, no propone razones para delinear su función y su significación en la propia sociedad. Sin embargo, en los primeros escritos de posguerra, redactados y publicados en el exilio de México, la temática del intelectual asume un protagonismo indiscutible. Al mismo tiempo, profundiza y desarrolla un cuadro completo en tomo al papel y al sentido de la figura del intelectual en la sociedad. Esto quiere decir que con la guerra y en medio de la contienda tuvo que perfilar y concretar las ideas abstractas y generales que poseía en torno a dicha figura o bien tuvo que plantear este tema que hasta ese momento había pasado desapercibido en su pensamiento. Son altamente reveladoras las palabras de Eugenio Imaz en el artículo que publica en España Peregrina bajo el título de «Pensamiento desterrado».

Soy un desterrado, un refugiado político. Soy un hombre. Nada menos que todo un hombre, que está en la distinción singular que a los sin patria nos hace el pais que nos recoge. Uno entre los demás. Uno, naturalmente, en mi oficio, que es donde yo me trato sobre todo con los demás. Mi oficio, ya no sé mi vocación, es de escritor. Mi único deber, como escritor, será, pues, no traicionar, en el escritor, al hombre.

Hasta que estalló la guerra civil en mi patria yo cumplía buenamente con este oficio y creia, con la mejor buena fe, cumplir también con mi deber de hombre. Escribía cuando me parecía tener algo que decir, me desentendía altivamente del confuso barullo de los gremios políticos y trataba de encontrar mi serenidad, de conciliar mi sino, en la dedicación desinteresada a la verdad. De esta postura, de esta tiesura, no me apeaba nadie.

Nadie. No había persona en el mundo que, conno decimos en España, me hiciera apear del burro. Pero los acontecimientos se precipitaron vertiginosamente en mi patria y quedé descabalgado y en el aire. Eché, o me echaron, pie a tierra y me puse a caminar, confundido entre la gente, los caminos ordinarios. Eché pie a tienra y, a mis años, aprendí a andar; aprendí a andar entre ríos de fuego y de sangre y por eso creo tener hoy el paso firme.

Este mi paso seguro de hombre de letras rehecho por la guerra no habrá estudios ni demostraciones nuevos que lo traben vacilante. No habrá filósofos. No habrá maestros. 
No habrá sociólogos. Porque la verdad que me sostiene es hija de la pasión más clarividente. La pasión, en mí, es la verdad de mi pueblo. Escandalosa verdad apasionada. Única verdad, ahora me doy cuenta, que he poseído en mi vida y que, por eso, me posee. De ella tendrán que salir las demás, todas las demás, las altas y las bajas. Si quiero cumplir con mi deber de escritor, es decir, de hombre [En busca..., pp. 62-63].

Merecia la pena reproducir esta larga cita por el gran interés de las afirmaciones. Del párrafo se pueden entresacar cuatro ideas centrales: primera, antes de la guerra se cumple la misión de intelectual de un plano meramente teórico; segunda, la guerra civil se erige en la maestra de una verdad basada en la razón del pueblo; tercera, esa verdad se aprende a fuego y sangre; cuarta, la misión del intelectual es no traicionar al hombre. De esta manera, se llega a un paradigma de sentido de gran relieve en el pensamiento de Eugenio Imaz: el intelectual depende del hombre-pueblo como las verdades del intelectual se subordinan a la verdad del pueblo.

En este contexto de presiones y pasiones, el intelectual tiene que comprometerse con la realidad de la historia y con el destino del hombre. Es la única forma de ser consecuente con las exigencias propias de una misión. Por eso, el verdadero intelectual no juega con puras entelequias sino con razones de existencia. El intelectual que no toma partido o bien uel intelectual que se pone en medio, no es intelectual ni hombre* (Topia..., p. 18) e inversamente, como afirma el filósofo «cuando el mundo está revuelto, alborotado, con sobresaltos de parto, hay que meterse en él para conocerlo y para, conociéndolo, hacerlo. Hay que tomar una postura y hay que tomar posiciones: o con las fuerzas creadoras, con el conocimiento, o contra las fuerzas creadoras, contra el conocimiento. Si para alguien hoy hay op- ción, es para el intelectual» (Topia..., p. 21). La misión y el destino del auténtico intelectual es su participación comprometida con la dinámica histórica y con el destino humano.

Plantear estos dos temas, piedras angulares de la cosmovisión ideológica de Eugenio Imaz, supone desentrañar un pensamiento para poder plantear con objetividad los temas-elementos constitutivos del organigrama filosófico. Según afirmaba en un trabajo anterior, "Eugenio Imaz defiende un claro finalismo para el proceso histórico del hombre, cuya etapa última será la eternidad humana o Humanidad. La historia, por tanto, es la expresión puntual del camino progresivo desde el humanismo de presente hasta la Humanidad de futuro [...] Este proceso de superación ascética $\mathrm{y}$ de maduración humana exige un decidido espíritu de sacrificio y una clara voluntad de heroísmo [...] La lección del finalismo histórico y la razón de la maduración humana implican un compromiso serio por parte del hombre, ya que el ser humano es el artífice real de su propia historia y, como tal, de la objetivación de la voluntad divina. Esta toma de conciencia y el compromiso consecuente suponen, a su vez, un estado de permanente vigilia. En este estado de concienciación y de alerta entra en juego el papel y la función del intelectuals (Eug, p. 171). Tal como podemos deducir de la cita, se establece el sentido profundo del intelectual entre las máximas de la dinámica histórica y del destino humano.

El filósofo donostiarra, respondiendo a unas claras influencias ideológicas cuyo origen se encuentra entre los ilustrados del siglo XVII, considera que la historia no puede ser el resultado del puro azar. Desde esta perspectiva, cada etapa histórica transciende el determinismo de la casualidad, porque el devenir humano en el tiempo no puede ser 
producto de la concatenación fortuita de los hechos o sucesos protagonizados por el hombre. La historia es la materialización puntual de la Idca Suprema, del Espíritu, en el tiempo. A su vez, partiendo de la premisa de que la sociedad humana, el pueblo en general, es el agente dinamizador de los cambios históricos, se llega a la conclusión de que Dios, el Espíritu, se manifiesta y se concreta en los comportamientos del pueblo, de forma que sus realizaciones en el tiempo histórico son en cada momento y en cada época la concreción de la voluntad divina. Así pues, la historia debe ser valorada como la revelación puntual de la divinidad. Bajo esta perspectiva, aceptar las decisiones libres del pueblo es asumir responsablemente el designio del espiritu y la finalidad transcendente de la historia.

El Espíritu, Dios, que vive con nosotros, vive a través de formas determinadas: son los pueblos. Pueblo, en general, es aquella forma o ley singular del Espíritu, a través de la cual únicamente el hombre puede producir algo eterno [La fe..., p. 44].

Toda la historia universal no es otra cosa que la realización del Espíritu. El Espiritu, por fin, después de un forcejeo dialéctico de milenios, ha llegado, en magnífico orto, a reconocerse a si mismo como libre, como libertad [La fe..., pp. 142-143].

Si en el primer fragmento se relacionan los principios del pueblo con eternidad en base al carácter vivo y presente del Espíritu, en el segundo se manifiesta la fuerza reveladora que otorga la divinidad al devenir humano, a la historia. De esta manera, se puede concluir con la identificación expresa entre manifestación puntual del Espiritu en el tiempo y dinámica histórica, de manera que todo cambio político o social en el contexto de la humanidad es simplemente la concreción y manifestación expresa de la voluntad divina en la historia.

Si todo presente es palabra del Espíritu, la actualidad, por lo menos la que plantea y de la que habla Eugenio Imaz en sus escritos, se identifica con la República, con los principios de libertad y democracia. Por eso, la democracia, es decir, el gobierno legítimo de la República, no sólo queda legitimada por ser expresión mayoritaria del pueblo, sino igualmente sacralizada por ser la manifestación de la voluntad del Espíritu. Desde el punto de vista de estos planteamientos, son lógicas las palabras que expone en su ensayo "En busca de nuestro tiempos:

La historia nos enseña que todos los pueblos marchan hacia la democracia [...] Pretender detener la democracia parecería cntonces luchar contra el mismo Dios [ La fe..., p. 145].

Sólo en la historia, en el mundo social, que es hechura del hombre, éste puede sentir la emoción divina del conocimiento creador. $X$ sólo la Historia, la nueva "ciencia nueva", puede ofrecernos una «demostración de hechon, una demostración histórica de la Providencia [Topia..., p. 84].

Plantear el carácter evolutivo de la dinámica histórica supone cuestionarse sobre su meta final o, si se prefiere, sobre el destino último del ser humano. Desde este punto de vista, el ensayista donostiarra, partiendo de los presupuestos ideológicos del humanismo renacentista, identifica la realidad del destino humano con la irrupción del tópico del homo novus encarnación en el tiempo del homo amans.

No es que añoremos tiempos pasados, no; añoramos, en verdad, tiempos futuros, como si ya hubiésemos estado en ellos, pero porque los añoramos entrañables, no queremos que a nombre de ningún credo político, filosófico, cientifico o tecnológioo [...] se maltra- 
te la semilla humana privándola de lo privativo suyo, del humus. ¿Cuántos milenios no habria que esperar, en el mejor de los casos, para que surgiera de nuevo, si es que surgía, no el homo faber, ni siquiera el homo sapiens, sino ya ese hombre que ya se perfila tras las cortinas de humo levantadas por la bomba atómica, el homo amans? [Luz..., p. 103].

En la cerrada lejania del horizonte se está fraguando en silencio la figura del hombre universal, consciente de sus tremendas limitaciones pero dueño, por eso mismo, de sus esperanzas [Luz,.., p. 209].

Según se puede deducir de las palabras de Eugenio Imaz, el hombre en un tiempo histórico tiene la obligación por misión y por destino de alcanzar las cotas de la perfección, de armonizar en una misma y única naturaleza su condición de hombre con su destino en el amor, generando ese nuevo ser que se conocerá como el homo amans. Proclamar la realidad del homo amans implica defender la razón de la utopía humanista, materializar el tópico de la edad dorada. Este tópico representa un mundo de valores absolutos, personificado arquetípicamente en el Espíritu, Ser Supremo, Perfección.

El binomio perfección-absoluto, personificado en el Espíritu de lo Absoluto, se opone al binomio imperfección-relatividad, representado por el ser humano. El hombre aspira al Absoluto-perfección, porque desea alcanzar los atributos propios de la divinidad. Por eso, si el Espíritu es amor, felicidad, armonía, justicia, paz, etc, la conquista de la divinidad, realización de la utopía, significa la materialización en el tiempo y en el espacio del amor, la paz, la justicia, en una palabra, de los valores absolutos. Este proceso transformativo arquetípico de la mariposa, «la mariposa emblema realista de la Resurrección" (Topia..., p. 51), como clara ejemplificación de la metamorfosis de lo imperfec- to $\mathrm{y}$ pedestre -gusano- en lo bello $\mathrm{y}$ celeste - mariposa- a través de un proceso de maduración intema-crisálida. La alegoría del gusano transformado en mariposa es ejemplo del destino del hombre y emblema de la utopía de la humanidad.

La humanidad por destino está llamada a gozar de una naturaleza perfecta en un mundo armónico regido por los valores absolutos. Pero antes de alcanzar las cotas de la perfección y de la armonia, tiene como misión la superación progresiva de todos los obstáculos y limitaciones que impone la propia imperfección de su naturaleza.

Ahora bien, la superación gradual de estas barrcras o impedimentos tiene que ser obra de la colectividad y no del individuo, ya que en definitiva el triunfo o el fracaso del proyecto humano se encuentra on las manos-acción de la humanidad-colectividad y no en las del hombre-individualidad. Solo en la unión fraterna, el hombre podrá conocer su auténtico ser y podrá hacer efectiva y real la utopia humanista del homo anans, del hombre universal. Al respecto, el escritor guipuzcoano es tan determinante como reiterativo:

Solo la humanidad, en su concepto, puede ser feliz, mejor dicho, digna de la felicidad. La humanidad, no el hombre, es el verdadero rey de la creación, su fin supremo. Si el género humano significa toda una serie de generaciones que se prolonga indefinidamente y se supone que esta serie se va aproximando necesariamente a la línea de su destino, que corre a su lado, no hay contradicción alguna en decir [...] que ningún miembro de todas las generaciones del género humano, sino únicamente la especie, alcanza por completo su destino [Topia..., p. 100].

El yo se encuentra a sf mismo cuando se entrega al tú, y sólo en esta entrega enteriza y personal a los demás y a la vida con los demás se le puede hacer al hombre transparente el Ser [Ltwz.., p. 139]. 
Según el sentido latente en el pensamiento de Eugenio Imaz, se llega a plantear la dimensión colectiva de la dinámica histórica y de la conquista del destino humano. El hombre-humanidad en medio de un esfuerzo solidario y $\mathrm{Co}$ lectivo y a través de un proceso de maduración llegará un buen día venturoso a adquirir un ser perfecto y una naturaleza plena. Será el día glorioso de la materialización de la utopía en una venturosa topía, de la superación del destino humano como proyecto-idea: EEl hombre universal no es una idea, sino una necesidad. Necesitamos el hombre universal [...] para encontrar encarnada en una vida la verdad que los sistemas sólo nos ofrecen en simulacro" (Luz..., p. 110).

Por eso, el hombre en su destino vale como realización y no tanto como proyecto. Sin embargo, la consecución de este destino depende de su voluntad y de sus obras: "el hombre tiene un destino, un esquema de hombre posible que tiene que llenar con sus obras» (Topia..., p. 24). Y su consumación la debe efectuar en el tiempo y en unión con todos los demás hombres: "[...] en el tiempo y en medio de sus compañeros, nace y se hace el hombre" (Topta..., p. 24). De esta manera, la realización del destino humano, la materialización de la utopía, presupone, por una parte, la razón del tiempo cronológico y, por otro lado, el principio de unidad solidaria.

Si la realización de la utopía humana, la conversión del hombre en ser-amor, homo amans, se emparenta con el tiempo y se subordina a la acción solidaria de la humanidad, es porque la utopía de ese hombre universal - homo amans es en sí una categoría historica. Como afirma el ensayista vasco, incidiendo en el pensamiento de Dilthey: «La totalidad de la naturaleza humana se halla en la historia» (Luz..., p. 71). De esta forma, como pescadilla que se muerde su pro- pia cola, la razón del destino humano nos remite al principio de la dinámica histórica, ya que la historia no sólo muestra el camino recortido por la humanidad desde sus origenes hasta el tiempo presente, también indica la dirección de esa marcha desde el presente hasta el futuro. "La historia se escribe desde el presente para el futuron ( $L u z . . .$, p. 182). De esta manera, se vuelve al punto de partida. El destino humano es la explicación de la historia y la historia es la justificación puntual y progresiva de dicho destino.

A su vez, como se afirmaba con anterioridad, el elemento sintonizador entre historia y destino es el hombre como colectividad, ya que no se puede olvidar que el Espíritu se manifiesta y materializa en el pueblo. Por eso, las realizaciones del pueblo en el tiempo histónico son la demostración y expresión de la voluntad del Espíritu entre los hombres. Se concluye, de esta manera, con la afirmación de que la realización del proceso histórico hacia la conquista de su destino final se halla en las manos del pueblo. El pueblo se convierte en sujeto agente de su propio destino $\mathrm{y}$ en hacedor de la voluntad divina en el mundo. El protagonismo del pueblo en el pensamiento de Eugenio Imaz es claro y rotundo. El pueblo se encuentra encumbrado por su misión, pero también se halla sometido a una gran responsabilidad, de donde nace la grandeza de su esperanza y la duda ante el riesgo.

En este estado entre grandeza y responsabilidades, entre esperanza y riesgos, etc., se ubican la función y el sentido del intelectual. Este es una especie de profeta y de conductor de pueblos. Tíene como misión la obligación de explicar la realidad y el futuro humanos $y$, al mismo tiempo, la de testimoniar el compromiso del hombre con su propio destino.

El intelectual por mision y por desig- 
nio es el poseedor y depositario del conocimiento humano. Este conocimiento no lo recibe de forma directa de la divinidad a través de la revelación, sino que lo debe tomar de la observación y del análisis de los comportamientos humanos y de las leyes históricas. Como el Espíritu se manifiesta en el hacer puntual de los pueblos, sólo en esa dinámica histórica emanada de las conductas del hombre puede encontrar el intelectual el auténtico saber humano y la verdadera expresión divina. El intelectual, estudiando las leyes del comportamiento humano y su proyección en la historia, puede llegar a conocer no sólo la realidad humana sino también esos grados de realidad divina que se hallan objetivados en la dinámica histórica. Poseyendo el saber, el intelectual tiene que devolver esos conocimientos a su lugar de procedencia: el pueblo. De esta manera y a través de la intercesión del intelectual, el pueblo toma conciencia de su verdadera naturaleza y de su auténtica finalidad. La misión del intelectual queda realizada en cuanto el pueblo asume, primero, el conocimiento, $y$, después, el compromiso. Se llega a dar como resultado final la identificación entre pueblo e intelectual.

Esta simbiosis de conocimiento y entrega entre el pueblo y el intelectual forma la síntesis de la dialéctica histórica en ese caminar progresivo desde el presente temporal hasta el futuro absoluto.

[...] la verdad no está en el cielo, poblado de intuiciones, sino en la ticrra, cn esta tierra que piso $[\ldots]$ entonces, no es contemplando como gano la verdad, sino combatiendo [Topía..., p. 17].

Porque el hombre no ha venido al mundo, cuando ha venido, para amar a Dios sobre todas las cosas, ni para estar por encima de ellas, como Dios, contemplándolas y complaciéndose en su juego, sino para hacerlas. En esta necesidad absoluta que tiene el hombre de saber a qué atenerse, para saber qué hacer, para hacer, está, según algunos, el origen de la sabiduria [Topía.., p. 23].

Yo no quiero meterme en libros de caballería, quiero decir, en filosofías [...] Lo que quiero es explicarme, buenamente [...] El mundo, el mundo nuestro, el histórico, no es una bola telescópica ni una micela microscópica. El mundo es algo que se está haciendo, que hacemos o deshacemos, que nos hace o nos deshace, que hacemos o deshacernos. No hay escape. Esta es la tragedia y la grandeza de nuestro destino [Topia.... p. 20].

No, cuando el mundo está revuelto, alborotado, con sobresalto de parto, hay que meterse en él para conocerlo y para, conociendolo, hacerlo. Hay que tomar una postura y hay que tomar posiciones: o con las fuerzas creadoras, con el conocimiento, o contra las fuerzas creadoras, contra el conocimiento. Si para alguien no hay opción, es para el intelectual [Topía..., p. 21].

Las citas se podrían multiplicar, pero las presentadas son suficientes para observar la importancia que la razón de cultura y hombre de cultura, intelectual, tiene para el pensador guipuzcoano. A su vez, a través de lós ejemplos seleccionados se puede rastrear con facilidad el sentido que estos aspectos, cultural e intelectual, presentan en el organigrama ideológico de Eugenio Imaz.

El papel del intelectual es difícil por ser arriesgado. Por misión y por designio tiene que comprometerse con la suerte del pueblo y con la dinámica de la historia para poder concretar la sabiduría auténtica entre los miembros de su misma colectividad, para que éstos, una vez concienciados, levanten el estandarte de la lucha superativa. El hombre tiene que vivir en un estado de continua revolución, siendo el intelectual el punto de referencia puntual en cada momento histórico. La postura del intelectual es decisiva en esa marcha hacia el siempre adclantc.

Al respecto, son claras las palabras 
del pensador vasco. Según afirmaba $\mathbf{E u}$ genio Ima $z$, ideas expuestas al principio de este trabajo, las posturas que asume el hombre se reducen a dos "o con las fuerzas creadoras, con el conocimiento, o contra las fuerzas creadoras, contra el conocimiento». Por eso mismo, no hay lugar ni jucgo en este concierto de continuo cambio para el intelectual que no se compromete: El intelectual que se pone en medio, no es intelectual ni hombre» (Topia..., p. 18). Si en la historia de la humanidad se exige al pueblo entrega y heroísmo, es lógico que esta lección de responsabilidad heroica se inicie con el intelectual. La suerte del intelectual se halla siempre unida a la suerte del pueblo, de forma que el binomio de intelectual-pueblo conforma la síntesis entre las razones de humanidad, tesis, y Espíritu, antítesis.

Todo proceso de síntesis supone un paso adelante hacia la asimilación completa del hombre-humanismo con el Espíritu-divinidad. Cuando la síntesis del pueblo-intelectual, nueva tesis en el siguiente paso del proceso dialéctico, se identifique con su posible antitesis se habrá superado el proceso histórico para conformar la última y definitiva tesis, unión completa entre hombre y Espíritu. Mientras no se llegue a este punto, la historia humana seguirá presentando un claro finalismo, cuya meta se hallara en el Espíritu, y cuyos protagonistas de conquista seguirán siendo el pueblo y el intelectual.

Aunque en el pensamiento del escritor donostiarra bullen y rebullen distintas ideologias de diferentes épocas, las utopías del renacimiento, el mito del progreso de la ilustración, los historicismos del siglo xIx, las ideas del institucionismo, etc., existe una realidad de pensamiento donde confluyen todos estos presupuestos $\mathrm{y}$ en donde Eugenio Imaz pudo perfectamente abrevar para dar fuerza y sentido a sus ideas perso- nales: el pensamiento republicano de la guerra, expresado y sintetizado de manera muy especial en el $I I$ Congreso $I n-$ temacional de Escritores Antifascistas y ampliado en sus pormenores ya en época de exilio en la revista España Peregrina. En ambos lugares se defendió la unión de destino para el hombre, el protagonismo indiscutible del pueblo en los ámbitos de la historia y de la cultura, la función orientadora $y$, en cierto sentido, salvífica del intelectual comprometido con la suerte y el destino de su pueblo. Desde otro punto de vista, en todos estos planteamientos, Eugenio Imaz comulga íntimamente con sus dos grandes amigos y compañeros: León Felipe y Juan Larrea. Desde todas estas perspectivas, se ve cómo el pensamiento de Eugenio Imaz, aunque presente influencias claras de diferentes escuelas de distintas épocas, se engasta con los presupuestos ideológicos de una de las posturas de un tiempo histórico bien delimitado: la versión republicana en los tiempos de la guerra civil y del consecuente exilio.

Desde la perspectiva de estas consideraciones, se comprende el papel un tanto protagonista que desempeña Eugenio Imaz entre los intelectuales de la «España peregrina». Como tal, se nos revela. como un declarado antifascista, para quien la utilización de la fuerza con el fin de imponerse a los designios del pueblo fue $y$ es un acto de barbarie $y$ deshumanización. Por eso mismo, la guerra civil es conceptuada como un aborto maldito de la historia. Inversamente, se siente y se compromete con el destino político de la república, no por ser republicano, sino porque era demócrata. Y tenía que ser demócrata, porque tanto vital como ideológicamente la democracia era la expresión política de la voluntad popular pero era también la expresión divina concretada en las decisiones libres y soberanas del pueblo. La 
razón de democracia explica y desvela las claves internas de las razones de dinamismo histórico y de destino humano. Así pues, desde estos presupuestos de fundamento democrático se entiende tanto la vida del ensayista vasco como se comprende el entramado ideológico de su pensamiento filosófico.

\section{LIBROS CITADOS}

Eugenio Imaz I: La fe por la palabra, San Sebastián, Univ. de Deusto, 1989, Cuademos Universitatios.

Eugenio Imaz II: Topia y utopía, San Sebastián, Uniw. de Deusto, 1988, Cuademos Universitarios.

Eugenio Inaz III Luz en la cavernd, San Sebastián, Univ. de Deusto, 1988, Cuadernos Universitarios.
Eugenio Imaz: En busca de maestro tiempo, San Sebastián, J.A. Ascunce (ed.), 1992.

Eugento 7maz: hombre, obta $y$ pensamiento (colec.), Madrid/México, Fondo de Cultura Económica, 1990 .

Ascunce, J.A.: Topias y utopias de Eugenio Imaz, Barcelona, Anthropos, 1991, Memoria Rota. Exilios y Heterodoxins. 